\title{
Chemokine receptors in gastric MALT lymphoma: loss of CXCR4 and upregulation of CXCR7 is associated with progression to diffuse large B-cell lymphoma
}

\author{
Alexander JA Deutsch ${ }^{1,2}$, Elisabeth Steinbauer ${ }^{3}$, Nicole A Hofmann ${ }^{1,2}$, Dirk Strunk ${ }^{1,2}$, \\ Tanja Gerlza ${ }^{1,2}$, Christine Beham-Schmid ${ }^{3}$, Helmut Schaider ${ }^{2,4,5}$ and Peter Neumeister ${ }^{1,2,5}$ \\ ${ }^{1}$ Division of Hematology, Department of Internal Medicine, Medical University Graz, Graz, Austria; ${ }^{2}$ Center \\ for Medical Research (ZMF), Medical University Graz, Graz, Austria; ${ }^{3}$ Institute of Pathology, Medical \\ University Graz, Graz, Austria and ${ }^{4}$ Cancer Biology Unit, Department of Dermatology, Medical University \\ Graz, Graz, Austria
}

\begin{abstract}
Chemokine receptors have a crucial role in the development and progression of lymphoid neoplasms. To determine the chemokine receptor expression profile in gastric mucosa-associated lymphoid tissue (MALT) lymphoma, we performed an expression analysis of 19 chemokine receptors at mRNA levels by using real-time RT-PCR, as well as of five chemokine receptors-CCR8, CCR9, CXCR4, CXCR6 and CXCR7-by immunohistochemistry on human tissue samples of Helicobacter pylori-associated gastritis, gastric MALT lymphoma and gastric extranodal diffuse large B-cell lymphoma originating from MALT lymphoma (transformed MALT lymphoma). Following malignant transformation from $H$. pylori-associated gastritis to MALT lymphoma, an upregulation of CCR7, CXCR3 and CXCR7, and a loss of CXCR4 were detected. The transformation of gastric MALT Iymphomas to gastric extranodal diffuse large B-cell lymphoma was accompanied by upregulation of CCR1, CCR5, CCR7, CCR8, CCR9, CXCR3, CXCR6, CXCR7 and XCR1. Remarkably, CXCR4 expression was exclusively found in nodal marginal B-cell lymphomas and nodal diffuse large B-cell lymphomas but not at extranodal manifestation sites, ie, in gastric MALT lymphomas or gastric extranodal diffuse large B-cell lymphomas. Furthermore, the incidence of bone marrow infiltration (16/51 with bone marrow involvement vs 35/51 with bone marrow involvement; Spearman $\rho=0467 P<0.001$ ) positively correlated with CXCR4 expression. CXCL12, the ligand of CXCR4 and CXCR7, was expressed by epithelial, endothelial and inflammatory cells, MALT lymphoma cells and was most strongly expressed by extranodal diffuse large B-cell lymphoma cells, suggesting at least in part an autocrine signaling pathway. Our data indicate that CXCR4 expression is associated with nodal manifestation and a more advanced stage of lymphomas and hence, might serve as useful clinical prognostic marker.

Modern Pathology (2013) 26, 182-194; doi:10.1038/modpathol.2012.134; published online 31 August 2012
\end{abstract}

Keywords: chemokines; chemokine receptor; CXCR4; CXCR7; MALT Iymphoma; transformed MALT lymphoma

The marginal zone B-cell lymphoma of the mucosaassociated lymphoid tissue (MALT lymphoma) shows histological features more closely resembling the mucosa-associated tissue than those of periph-

Correspondence: AJA Deutsch, PhD, Division of Hematology, Department of Internal Medicine, Center for Medical Research (ZMF), Medical University Graz, Auenbruggerplatz 38, Graz 8036, Austria.

E-mail: alexander.deutsch@medunigraz.at

${ }^{5}$ Thease authors contributed equally to this work.

Received 19 April 2012; revised 3 July 2012; accepted 3 July 2012; published online 31 August 2012 eral lymph nodes. MALT lymphoma arises with the highest frequency in the MALT of the gastrointestinal tract. For the development of MALT lymphomas, a long-lasting chronic inflammation induced by Helicobacter pylori gastritis provides the pathogenetic background at these sites. ${ }^{1}$

Chemokines, also known as proinflammatory, chemotactic cytokines, represent a large superfamily of peptides with diverse biological functions involved in organogenesis, hematopoesis and inflammatory processes. Chemokines interact with a target cell by binding to G-protein-coupled chemokine receptors. ${ }^{2-4}$ The homeostatic transport of precursor 
$\mathrm{B}$ cells to secondary lymphoid tissue is essential for B-cell development. CCR6, CCR7, CXCR3, CXCR4 and CXCR5 have a crucial role in this homing process, and therefore, the group of these five chemokine receptors is called B-cell homeostatic chemokine receptors. ${ }^{5-7}$ The activation-dependent chemokine receptors, which are expressed on effector leukocytes (including activated effector/memory T cells) in response to inflammatory cytokines, exert an essential role in inflammation and are responsible for migration toward a chemokine gradient produced by inflamed cells. ${ }^{2}$ Further, different patterns of chemokine receptor expression identified in different malignant B-cell subsets suggest that these chemokine receptors are functional and have a crucial role in malignant B-cell circulation leading to the emergence of monoclonal B cells and, eventually to transformation. ${ }^{8-11}$ The development of chemokine antagonists and their use in clinical trials for a variety of diseases shows the potential of chemokine receptors for molecular-targeted therapy. ${ }^{12}$

The aim of the present study was to identify expression patterns of 19 chemokine receptors of non-neoplastic stomach specimens, $H$. pyloriassociated gastritis, gastric MALT lymphomas and of extranodal diffuse large B-cell lymphoma arising from MALT lymphoma (transformed MALT lymphoma) in the stomach. Here, we show that the chemokine receptor expression profiles of gastric MALT lymphomas differ substantially to those of extranodal diffuse large B-cell lymphoma. Our data provide evidence that the stepwise development of gastric MALT lymphoma from a non-neoplastic event to $H$. pylori-associated gastritis to MALT lymphoma and finally to overt extranodal diffuse large B-cell lymphoma is accompanied by deregulation of activation-dependent and B-cell homeostatic chemokine receptors. Most importantly, CXCR4 expression correlates with bone marrow infiltration and lymhomagenesis at nodal sites, whereas loss of CXCR4 and gain of CXCR7 is associated with the high-grade progression to the aggressive extranodal diffuse large B-cell lymphoma. Hence, CXCR4 expression correlates with a more advanced stage and could therefore serve as useful clinical prognostic marker.

\section{Materials and methods}

\section{Materials}

Lymphoma entities were classified according to the WHO classification of lymphoid neoplasms. ${ }^{13}$ Methylene-stained sections of formalin-fixed, paraffinembedded lymphoma tissue containing $>80 \%$ lymphoma cells were manually macrodissected by an experienced pathologist using a disposable, sterile, 30-gauge needle under direct light microscopic visualization and were further processed for RNA isolation. Attention was paid that cases of extranodal diffuse large B-cell lymphoma comprised at least-established by morphology and immunohistochemistry-one focus of a low-grade lymphoma component considering these lymphomas as 'transformed MALT lymphomas'. ${ }^{14}$

The determination of the chemokine receptors mRNA expression profiles was performed on 10 gastric MALT lymphomas, 10 extranodal diffuse large B-cell lymphoma of the stomach, $6 \mathrm{H}$. pyloriassociated gastritis, 6 non-neoplastic stomachs, as well as on 16 nodal diffuse large B-cell lymphoma, 6 nodal marginal B-cell lymphomas and on 4 samples of peripheral blood B cells.

For immunohistochemical analysis of CCR8, CCR9, CXCR4, CXCR6, CXCR7 and CXCL12 (SDF-1 $\alpha), 21$ gastric MALT lymphomas (4 with bone marrow involvement and 17 without), 6 extranodal diffuse large B-cell lymphomas and $4 \mathrm{H}$. pylori-associated gastritis, and additionally for CXCR4 and CXCR7, 10 nodal diffuse large B-cell lymphomas and 6 nodal marginal zone B-cell lymphomas were used. To obtain knowledge about the expression profile of these four chemokine receptors on B cells of the marginal zone, four spleen samples from healthy donors were immunohistochemical analyzed.

The study was in agreement with the guidelines for the use of human material in research, issued by the local ethics committee.

\section{RNA Isolation, cDNA Synthesis and Real-Time PCR}

Total RNA isolation and cDNA synthesis of formalin-fixed, paraffin-embedded tissue samples of peripheral B isolated from blood of four healthy donors was performed as previously described. ${ }^{15,16}$

The real-time PCR and calculation of the expression levels were performed according to a protocol previously reported by Seidl et al. ${ }^{17}$ The nucleotide acid sequences for the primers and probes used for the determination of the expression levels of 19 chemokine receptors are shown in the Supplementary Table S1.

\section{Immunohistochemical Analyses for CCR1, CCR5, CXCR6 and XCR1}

Formalin-fixed, paraffin-embedded tissue was stained after pretreatment with Target Retrieval Solution (Dako, Glostrup, Denmark) using the DakoCytomation automated immuno-stainer and iView detection system (Ventana Medical System, Tucson, AZ, USA). Primary antibodies to CCR8 (1:400), CCR9 (1:250) and CXCR4 (1:200) were purchased from Abcam (Cambridge, Great Britain); CXCR6 (1:100) from MBL (Woburn, MA, USA); CXCR7 (1:100) from Acris (Herford, Germany); CD3 (1:50), CD20 (1:200), CD68 (1:200), MIB-1 (1:200) from Dako; CXCL12 (1:50) from R\&D (Minneapolis, MN, USA); Vs38C (1:100) from Dako; and XCR1 from Acris (1:1000; Hiddenhausen, Germany). For control purposes, tissues known to contain the 
respective antigens were included (positive controls). Replacement of the primary antibody by normal serum always revealed negative results (negative controls). Scoring of tissue slides and determination of the immunoreactive score (IRS) was performed as previously described by our group. ${ }^{16}$

\section{Statistical Analysis}

Statistical analysis was performed by using SPSS 15.0 (SPSS Inc., Chicago, IL, USA) as previously described by our group. ${ }^{16}$

\section{Results}

The Chemokine Receptor Expression Pattern is not Influenced by Intratumoral Inflammatory Cells

The occurrence of mRNA transcripts for CCR1, CCR5, CCR6, CCR7, CCR9, CCR10, CXCR1, CXCR2, CXCR3, CXCR4, CXCR5, CXCR6 and CXCR7 in pheripheral B cells was consistent with previously published data, ${ }^{18,19}$ demonstrating the suitability of the real-time PCR assays.

Analyses of the intratumoral $\mathrm{T}$ cells $(C D 3+)$, macrophages $(C D 68+)$ and plasma cells $(V s 38 C+)$ are included in Table 1 to further document the morphological variation of the two lymphoma categories. No correlation was observed between the percentage of $C D 3+, C D 68+$ and Vs38C + cells and the chemokine receptor expression profile, suggesting that the chemokine receptor expression pattern is determined by the lymphoma cells and not by intratumoral inflammatory cells.

\section{The Proliferation Rate of MALT Lymphomas and Extranodal diffuse large B-Cell Lymphomas Correlates with CCR9 Expression}

To study whether the chemokine receptor expression profile has any impact on the proliferation rate of the gastric MALT lymphomas and extranodal diffuse large B-cell lymphomas, Ki67 staining was carried out on 10 gastric MALT lymphomas and on 10 extranodal diffuse large B-cell lymphomas of the stomach and correlated to the chemokine receptor expression profile. The proliferation rate of the gastric MALT lymphomas was on average $5.7 \%$ (range: $3-7 \%$ ) and $67 \%$ for the extranodal diffuse large B-cell lymphomas (range: 30-90\%; Table 1). On comparing the proliferation rate of both lymphoma entities to the chemokine receptor mRNA expression profile, a significant positive correlation (Spearman $\rho 0.893$ and $P<0.001$ ) for CCR9 and a tendency of a positive correlation (Spearman $\rho 0.651$ and $P=0.081$ ) for $C X C R 7$ was observed.

\section{Differential Expression of CC Chemokine Receptor Levels During MALT Lymphomagenesis}

CCR7-as member of the B-cell homeostatic chemokine receptors $-{ }^{5-7}$ was most highly expressed in all

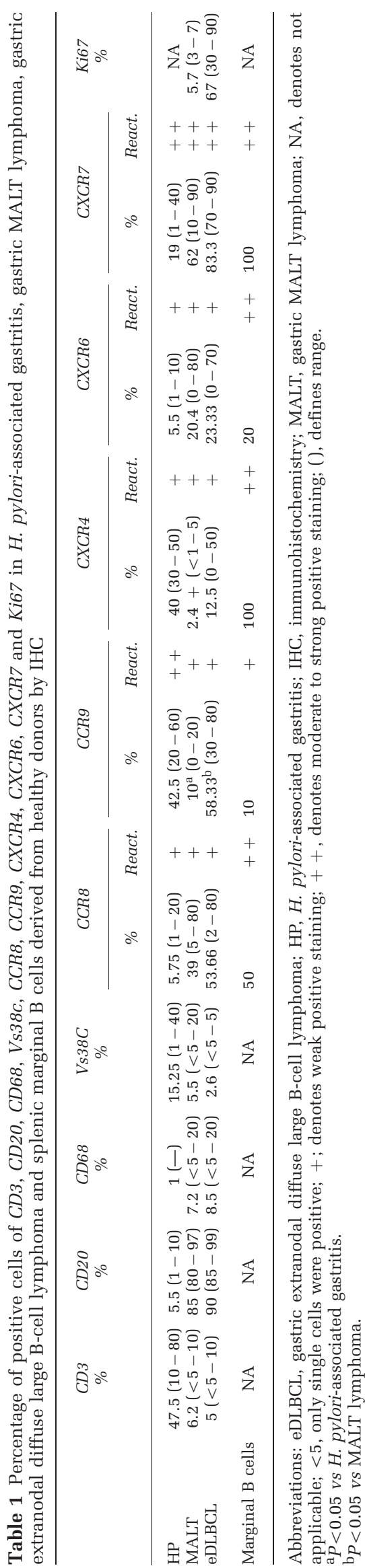


extranodal diffuse large B-cell lymphoma samples (Table 2 and Figure 1). At lower levels, CCR7 was also detectable in 7 of the 10 MALT lymphoma samples, in all $H$. pylori-associated gastritis samples and in all peripheral B cells, but was entirely lacking in the non-neoplastic stomach control samples.

CCR1, CCR5, CCR8 and CCR9-as members of the activation-dependent chemokine receptors- ${ }^{2}$ showed a similar expression profile in the lymphoma specimens (Table 2 and Figure 1). All four receptors were most highly expressed in the majority of extranodal diffuse large B-cell lymphoma samples. CCR1 and CCR5 were additionally expressed in 8 of the 10 gastric MALT lymphoma samples in all $H$. pylori-associated gastritis and in the majority of non-neoplastic stomach samples, as well as in peripheral B cells. CCR 8 and CCR9 were expressed in 4 of the 10 and in 2 of the 10 MALT lymphoma samples. CCR8 expression was only found in half of $H$. pylori-associated gastritis (three out of six) and in a minority of non-neoplastic stomach samples (one out of six), and its expression was entirely lacking in peripheral B cells. CCR9 expression was undetectable in $H$. pylori-associated gastritis and non-neoplastic stomach specimens, whereas it was expressed in all peripheral B cells.

mRNA expression of CCR2, CCR3, CCR4, CCR6 and CCR10 expression was either heterogeneous or missing and thus no significant differences within the study groups were observed.

In summary, the development of gastric MALT lymphoma is associated with increased CCR7 expression, whereas during high-grade transformation upregulation of CCR1, CCR5, CCR8 and CCR9 occurs.

\section{Differential Expression of CXC, CX3C and XC Chemokine Receptors during MALT Lymphomagenesis}

In the group of the B-cell homeostatic chemokine receptors-CXCR3, CXCR4 and CXCR5 $-{ }^{5-7}$ CXCR 4 expression was differentially regulated when compared with CXCR3 and CXCR5 (Table 2 and Figure 2). CXCR3 and CXCR5 were most highly expressed in all samples of the extranodal diffuse large B-cell lymphoma and in the peripheral B cells, but were undetectable in stomach control samples.
CXCR3 expression was found in some (2 of 6) $H$. pylori-associated gastritis-and in MALT lymphoma samples (5 of 10)-whereas CXCR5 was expressed in all $H$. pylori-associated gastritis and in 8 of 10 MALT lymphoma samples. The expression profiles of CXCR3 and CXCR5 were consistent with previously reported results in non-Hodgkin's lymphoma. ${ }^{8,9}$ CXCR4 expression was detectable in the majority of peripheral B cells (three of four) and $H$. pylori-associated gastritis (five of six) samples, in three of 10 extranodal diffuse large B-cell lymphoma samples, whereas its expression was lacking in all non-neoplastic stomach samples and MALT lymphoma samples.

The activation-dependent chemokine receptors were also predominantly expressed in extranodal diffuse large B-cell lymphoma samples, CXCR6 in all specimens, CXCR7 in 9 of the 10 extranodal diffuse large B-cell lymphoma samples and XCR1 in 8 of the 10 extranodal diffuse large B-cell lymphoma samples (Table 2 and Figure 2). CXCR6 and CXCR7 expression was also found in all pCD19+ samples, but was virtually absent in control samples, and was moderately expressed in $H$. pylori-associated gastritis samples and MALT lymphoma samples. On the contrary, XCR1 expression was detected in all non-neoplastic stomach samples, in 3 of 6 $H$. pylori samples and in 2 of 10 MALT lymphoma samples.

CXCR1, CXCR2 and CX3CR1 were heterogeneously expressed and no significant differences within the analyzed groups were observed.

In summary, the development of gastric MALT lymphoma is associated with increased CXCR3 and CXCR7 expression, and loss of CXCR4. During high-grade transformation upregulation of CXCR6, CXCR7 and XCR1 is observed.

\section{Immunohistochemical Analyses Confirms Loss of CXCR4 and Upregulation of CXCR7 in the Development of Gastric MALT Lymphoma}

Owing to their consistently high mRNA expression level in all MALT- and extranodal diffuse large B-cell lymphoma samples compared with their pCD19+ counterpart cells, immunohistochemical analyses of five chemokine receptors (CCR8, CCR9,

Table 2 mRNA expression of CC and CXC receptors in peripheral CD19 + B cells, non-neoplastic stomach, $H$. pylori-associated gastritis, gastric MALT lymphoma and extranodal diffuse large B-cell lymphoma

\begin{tabular}{|c|c|c|c|c|c|c|c|c|c|c|c|}
\hline & CCR1 & CCR5 & CCR7 & CCR 8 & CCR9 & CXCR3 & CXCR4 & CXCR5 & CXCR6 & CXCR7 & XCR1 \\
\hline B cell & $4 / 4$ & $4 / 4$ & $4 / 4$ & $0 / 4$ & $4 / 4$ & $4 / 4$ & $3 / 4$ & $3 / 4$ & $4 / 4$ & $4 / 4$ & $0 / 4$ \\
\hline Stomach & $4 / 6$ & $6 / 6$ & $0 / 6$ & $1 / 6$ & $0 / 6$ & $0 / 6$ & $0 / 6$ & $0 / 6$ & $1 / 6$ & $0 / 6$ & $6 / 6$ \\
\hline $\mathrm{HP}$ & $6 / 6$ & $6 / 6$ & $6 / 6$ & $3 / 6$ & $0 / 6$ & $2 / 6$ & $5 / 6$ & $6 / 6$ & $5 / 6$ & $4 / 6$ & $3 / 6$ \\
\hline MALT & $8 / 10$ & $8 / 10$ & 7/10 & $4 / 10$ & $2 / 10$ & $5 / 10$ & $0 / 10$ & $8 / 10$ & $5 / 10$ & $7 / 10$ & $2 / 10$ \\
\hline eDLBCL & $10 / 10$ & $10 / 10$ & $10 / 10$ & $10 / 10$ & $9 / 10$ & $9 / 10$ & $3 / 10$ & $10 / 10$ & $10 / 10$ & $9 / 10$ & $8 / 10$ \\
\hline
\end{tabular}

Abbreviations: B cell, peripheral B cells; eDLBCL, gastric extranodal diffuse large B-cell lymphoma; HP, H. pylori-associated gastritis; MALT, gastric MALT lymphoma; Stomach, non-neoplastic gastric tissue. 

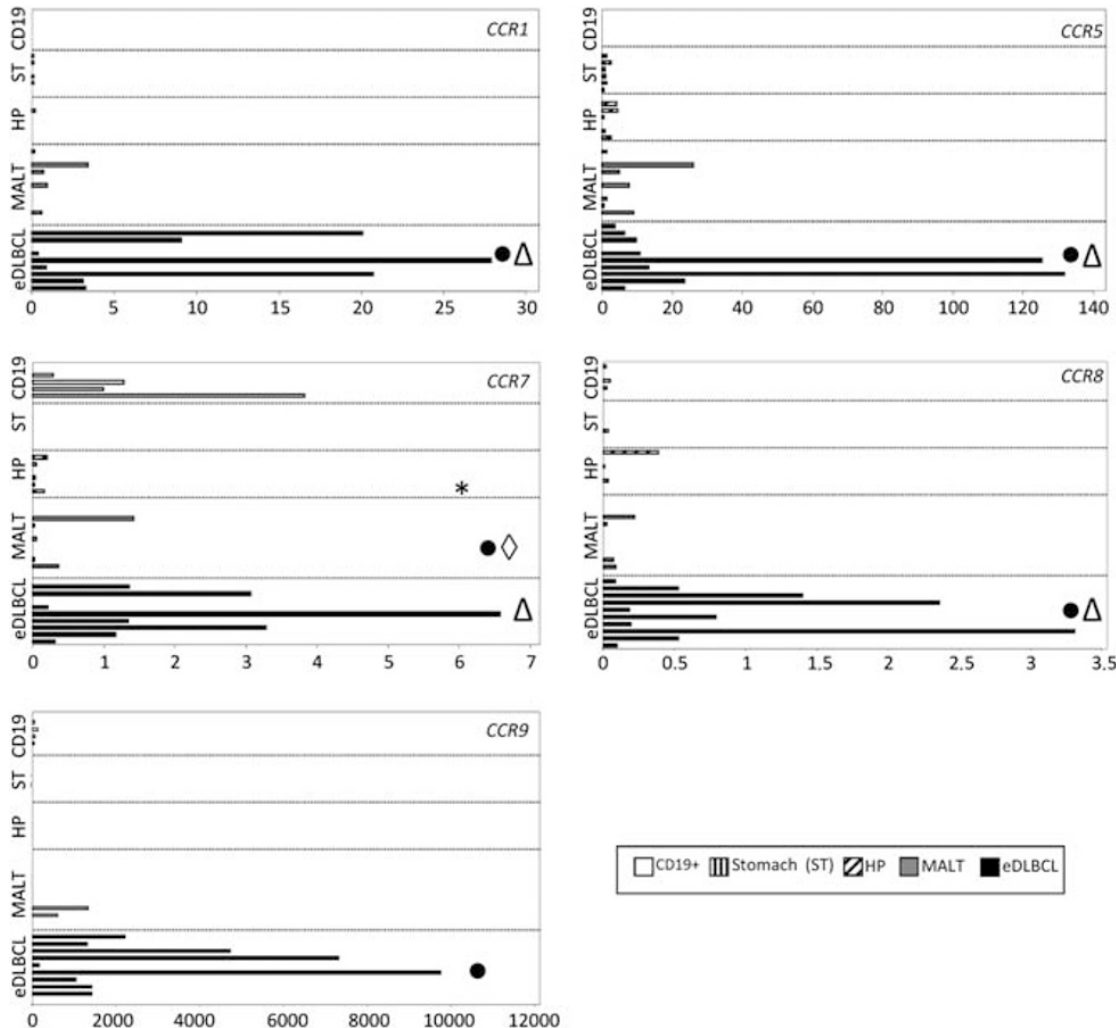

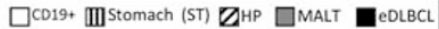

Figure 1 CC chemokine receptor mRNA profile of CD19+ cells, non-neoplastic stomach, $H$. pylori-associated gastritis, gastric MALT lymphoma and extranodal diffuse large B-cell lymphoma. Each bar represents a specimen. Values of gene expression are calculated as relative expression. Dots, significantly deregulated chemokine receptors compared with CD19+ cells; asteriks, significantly deregulated chemokine receptors of $H$. pylori-associated gastritis compared with stomach; rhombuses, significantly deregulated chemokine receptors of MALT lymphoma compared with $H$. pylori-associated gastritis; triangles, significantly deregulated chemokine receptors of $H$. pylori extranodal diffuse large B-cell lymphoma compared with MALT lymphoma. CD19 denotes peripheral B cells; eDLBCL, gastric extranodal diffuse large B-cell lymphoma; HP, H. pylori-associated gastritis; MALT, gastric MALT lymphoma; ST, nonneoplastic stomach.

CXCR6 and CXCR7, and of CXCR4)-because of the complete lack in gastric MALT lymphomas and in the majority of extranodal diffuse large B-cell lymphomas-were performed. As controls, marginal zone B cells of four spleens derived from healthy donors were included. When comparing protein levels with mRNA expression, a significant positive correlation for CCR8 (Spearman $\rho=0.732, P<0.01$ ), for CXCR4 (Spearman $\rho=0.573, \quad P=0.03$ ), for CXCR6 (Spearman $\rho=0.780, \quad P<0.01$ ) and for CXCR7 (Spearman $\rho=0.720, P<0.01$ ) was found, whereas for CCR9, a clear positive trend (Spearman $\rho=0.486, P=0.066$ ) was observed, thereby validating our RT-PCR results.

Expression of all five receptors was found on marginal zone $\mathrm{B}$ cells with different percentages: CCR8 and CXCR6 were strongly expressed on 50 and $20 \%$ of marginal zone B cells, CCR9 moderately on $10 \%$ of marginal zone B cells, and CXCR4 and CXCR7 strongly on all marginal zone B cells (Table 1).

In $H$. pylori-associated gastritis, inflammatory cells exhibited a moderate expression of CCR8 (5.75\%), CXCR6 (5.5\%) and CXCR7 (19\%), whereas more cells stained positive for CXCR4 (40\%) and CCR9 (42.5\%; Tables 1 and 3 and Figure 3).

In gastric MALT lymphoma specimens, $39 \%$ of malignant cells showed moderate CCR 8 expression; however, considerable expression was also evident on centroblasts in reactive lymphatic follicles (IRS: 1.64; Tables 1 and 3 and Figure 3). CCR9 imunohistochemical reactivity was moderately apparent in only $10 \%$ of malignant B cells in the majority of MALT lymphomas (IRS: 0.93; Tables 1 and 3 and Figure 3). Like CCR8, CCR9 reactivity was also found on centroblasts in reactive lymph follicles. A total of $20.4 \%$ of MALT lymphoma cells, centroblasts of reactive lymphatic follicles and endothelial cells of the surrounding tissue moderately expressed CXCR6 (IRS: 1.02; Tables 1 and 3 and Figure 3). It was also obvious that blasts in the lymphomas showed a stronger CCR8, CCR9 and CXCR6 expression than the infiltrating small neoplastic lymphocytes. In all gastric MALT lymphomas, on average $2.4 \%$ of malignant B cells showed a moderate CXCR4 expression (IRS: 0.14), whereas CXCR7 was strongly expressed on $62 \%$ of malignant $\mathrm{B}$ cells (IRS on average 11; Tables 1 and 3 and 

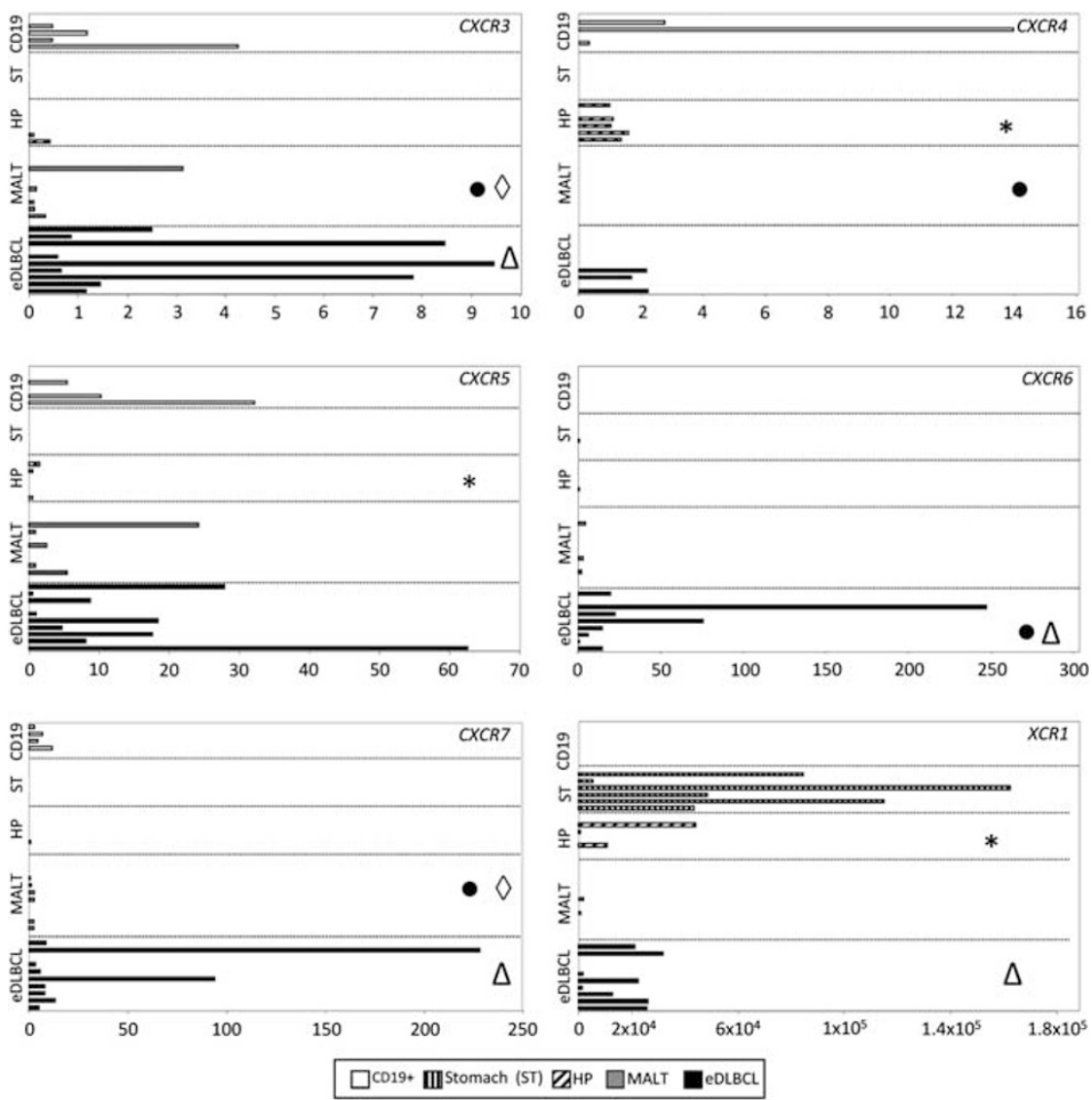

Figure 2 CXC chemokine receptor and XCR1 mRNA profile of pCD19+ cells, non-neoplastic stomach, H. pylori-associated gastritis, gastric MALT lymphoma and extranodal diffuse large B-cell lymphoma. Each bar represents a specimen. Values of gene expression are calculated as relative expression. Dots, significantly deregulated chemokine receptors compared with CD19+ cells; asteriks, significantly deregulated chemokine receptors of $H$. pylori-associated gastritis compared with stomach; rhombuses, significantly deregulated chemokine receptors of MALT lymphoma compared with $H$. pylori-associated gastritis; triangles, significantly deregulated chemokine receptors of $H$. pylori eDLBCL compared with MALT lymphoma. CD19 denotes peripheral B cells; eDLBCL, gastric extranodal diffuse large B-cell lymphoma; HP, H. pylori-associated gastritis; MALT, gastric MALT lymphoma; ST, non-neoplastic stomach.

Figure 3). Considerable expression of CXCR4 and CXCR7 was also evident on endothelial cells and on centroblasts in reactive lymphatic follicles.

The majority of malignant $\mathrm{B}$ cells in extranodal diffuse large B-cell lymphoma moderately expressed CCR8 (53.7\%, IRS on average 5.01; Tables 1 and 3 and Figure 3) and CCR9 (58.3\%, IRS on average 1.275; Tables 1 and 3 and Figure 3), whereas moderate CXCR6 (23.3\%, IRS 2.35; Tables 1 and 3 and Figure 3) and CXCR4 (12.5\%, IRS on average 0.39; Tables 1 and 3 and Figure 3) expression was present on a minority of extranodal diffuse large B-cell lymphoma cells. The only chemokine receptor that was strongly expressed on $83.3 \%$ of extranodal diffuse large B-cell lymphoma cells was CXCR7 (IRS: 14.8; Tables 1 and 3 and Figure 3).

Additionally, immunohistochemical analyses for CXCR4 and CXCR7 of Peyer's patches in nonneoplastic small intestine of four donors was performed. Around 80 (range 70-90\%) and 100\% of lymphocyte in the Peyer's patches express CXCR4 and CXCR7 (data not shown), indicating that the loss of CXCR4 is a specific phenomenon for gastric MALT lymphomas and extranodal diffuse large B-cell lymphomas of the stomach.

CXCL12 is Expressed in H. pylori-Associated Gastritis, Gastric MALT Lymphomas and Extranodal Diffuse Large B-cell Lymphoma of the Stomach

To further investigate a potential autocrine stimulation of CXCR4 and CXCR7, the expression level of their ligand CXCL12 $20-22$ was analyzed by immunohistochemistry.

In $H$. pylori-associated gastritis, strong CXCL12 expression was found in epithelial cells and in inflammatory cells (macrophages, dendritic cells and reactive blasts; Figure 4a). Additionally, single lymphoma cells of gastric MALT lymphoma and a significantly higher amount of around 18\% (single cells up to $30 \%$ ) lymphoma cells of extranodal diffuse large B-cell lymphoma of the stomach strongly express CXCL12 $(P<0.01$; Figure 4a). 


\section{Manifestation Site of Nodal and Extranodal Lymphomas is Guided by Differential CXCR4 and CXCR7 Expression}

The RNA expression profiles of CXCR4 and CXCR7 in extranodal and nodal lymphomas were determined: 10 gastric MALT lymphomas and 10 extranodal diffuse large B-cell lymphoma were compared with 6 nodal marginal zone B-cell lymphomas and 16 nodal diffuse large B-cell lymphomas. Transcripts of CXCR4 were almost exclusively found in all nodal marginal zone B-cell lymphomas and nodal diffuse large B-cell lymphoma but only in three extranodal diffuse large B-cell lymphomas and in none of the MALT lymphomas (Figure 4b). Immunohistochemical analyses of CXCR4 and CXCR7 in extranodal and nodal NHLs confirmed the significantly lower CXCR4 expression in extranodal vs nodal lymphomas (45-fold reduction in extranodal diffuse large B-cell lymphoma compared with nodal diffuse large B-cell lymphoma, $P=0.01$; 66 -fold reduction in gastric MALT compared with nodal marginal zone B-cell lymphomas, $P=0.016$; Figure 4c).

\section{CXCR4 is Associated With Bone Marrow Infiltration}

As CXCR4 has a role in cell homing of malignant hematopoiesis, hematopoetic stem cells, as well as cancer cells of solid tumors to the bone marrow, ${ }^{23-28}$ CXCR4 expression and bone marrow infiltration were determined. A significant correlation of CXCR4 expression and bone marrow involvement comprising all lymphoma entities (bone marrow involvement $(n=16 / 51)$ vs $(n=35 / 51 \mathrm{w} / \mathrm{o}$ bone marrow involvement; Spearman $\rho=0.467 P<0.001$, Table 4) was found. However, probably due to small sample size, no significant difference in CXCR4 expression levels between gastric MALT lymphomas with bone marrow involvement $(n=4)$ and those without bone marrow involvement $(n=21)$ was observed $(P=0.835)$. In contrast, in nodal lymphomas (nodal diffuse large B-cell lymphoma and nodal marginal zone B-cell lymphomas), CXCR4 expression was significantly $(8 \times)$ higher expressed in the group of lymphomas with bone marrow infiltration $(n=12)$ compared with those without bone marrow infiltration $(n=22 ; P=0.025)$, indicating the potential role of CXCR4 in the dissemination properties of nodal lymphomas.

\section{Chemokine Receptor Patterns in the Model of Gastric MALT Lymphomagenesis}

In a model of gastric MALT lymphomagenesis from a benign lesion to overt malignancy, four of five B-cell homeostatic chemokine receptors ${ }^{5-7}$ (CCR7, CXCR3, CXCR4 and CXCR5) and seven activation-dependent chemokine receptors (CCR1, CCR5, CCR8, CCR9, CXCR6, CXCR7 and XCR1) were differentially expressed $(P<0.001$; Figures $5 \mathrm{a}$ and $\mathrm{b})$. 


\section{H. pylori associated} gastritis
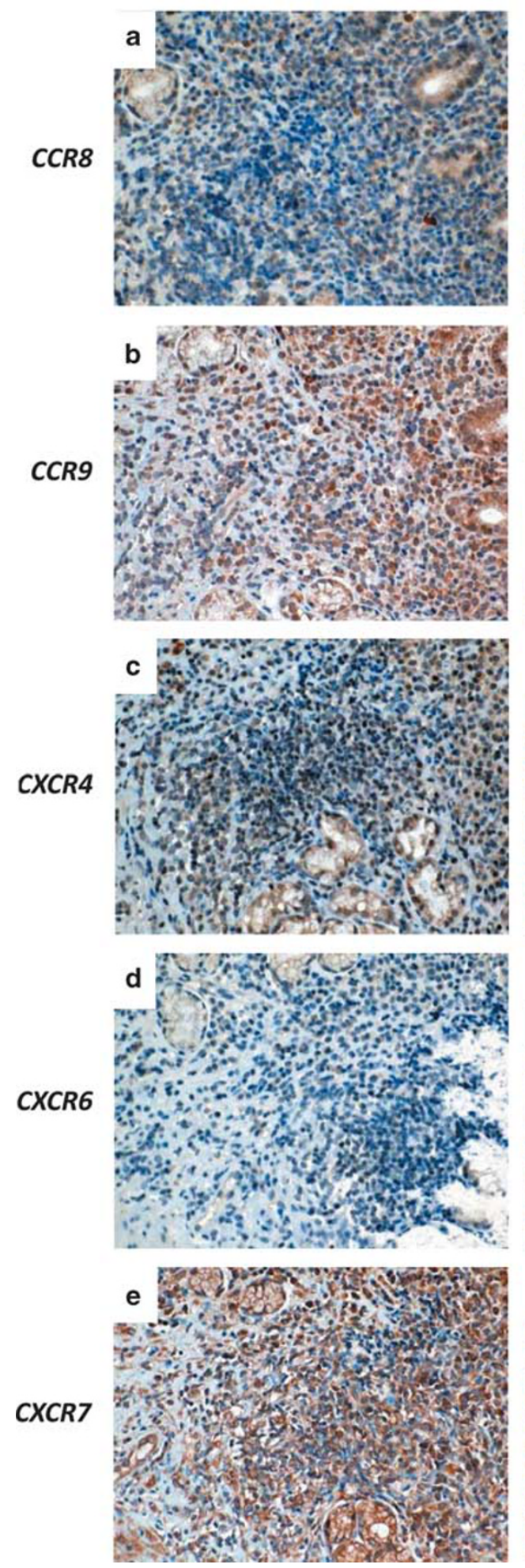

MALT lymphoma
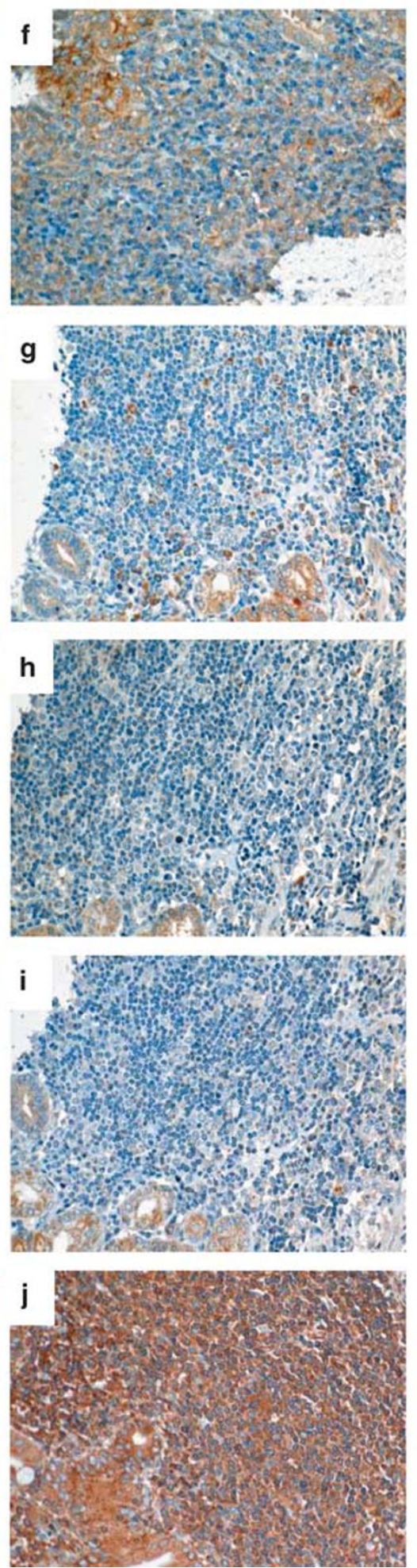

\section{extranodal diffuse large} B cell lymphoma
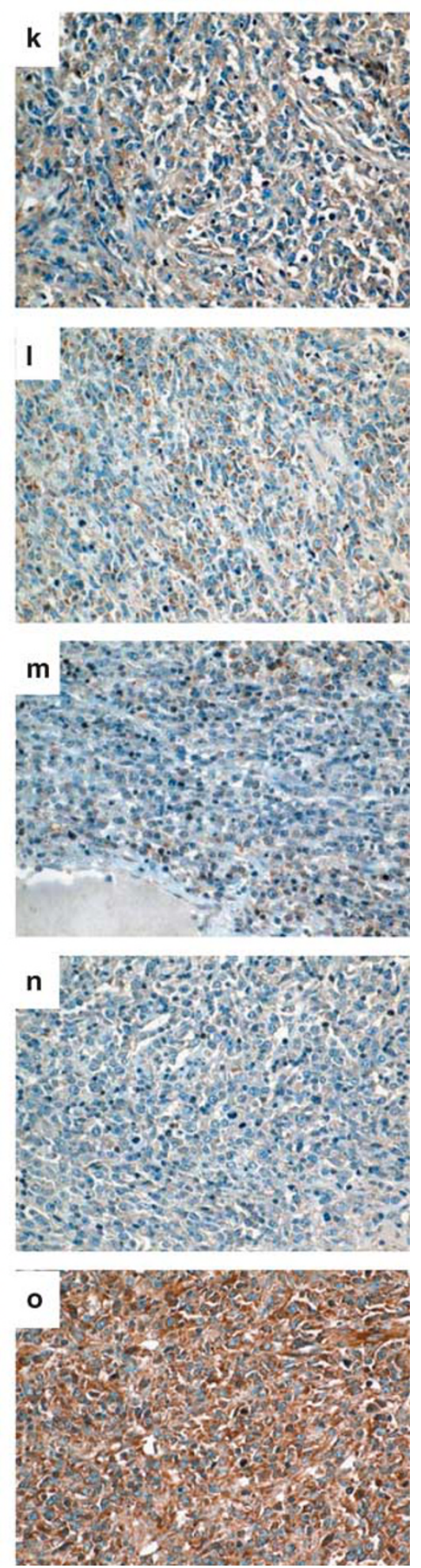

Figure 3 Immunohistochemistry of CCR8, CCR9, CXCR4, CXCR6 and CXCR7 in H. pylori-associated gastritis, gastric MALT lymphoma and extranodal diffuse large B-cell lymphoma. (a-e) Immunohistochemistry for CCR8, CCR9, CXCR4, CXCR6 and CXCR7 in H. pyloriassociated gastritis demonstrating positivity at varying degree. $(\mathbf{f}-\mathbf{j})$ Expression levels for the above mentioned chemokine receptors on gastric MALT lymphoma cells; CXCR4 expression was missing on the majority of malignant B cells. (k-o) Strong expression of CCR8, CCR9 and CXCR7 was found on the majority of extranodal diffuse large B-cell lymphoma cells. CXCR6 was expressed only in a minority of extranodal diffuse large B-cell lymphomas, whereas CXCR4 expression was just detectable on a minority of extranodal diffuse large B-cell lymphoma cells. 


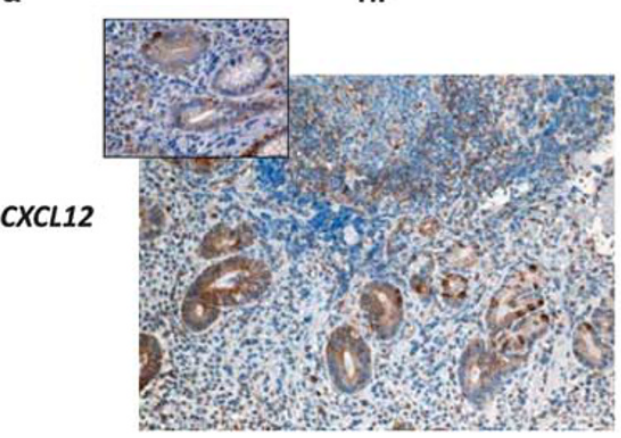

MALT

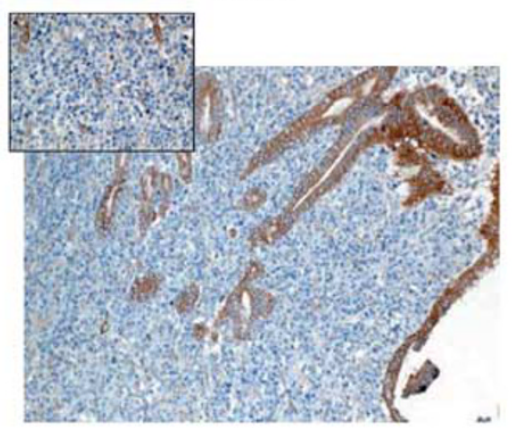

eDLBCL

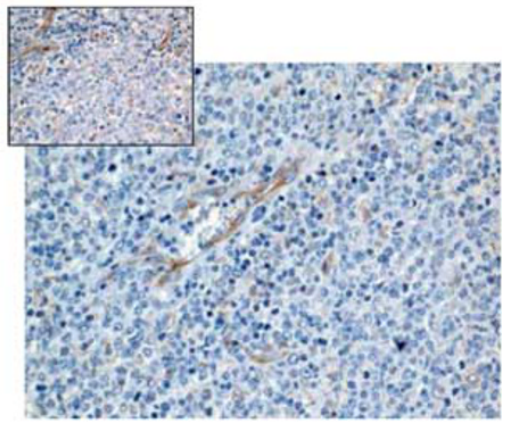

b
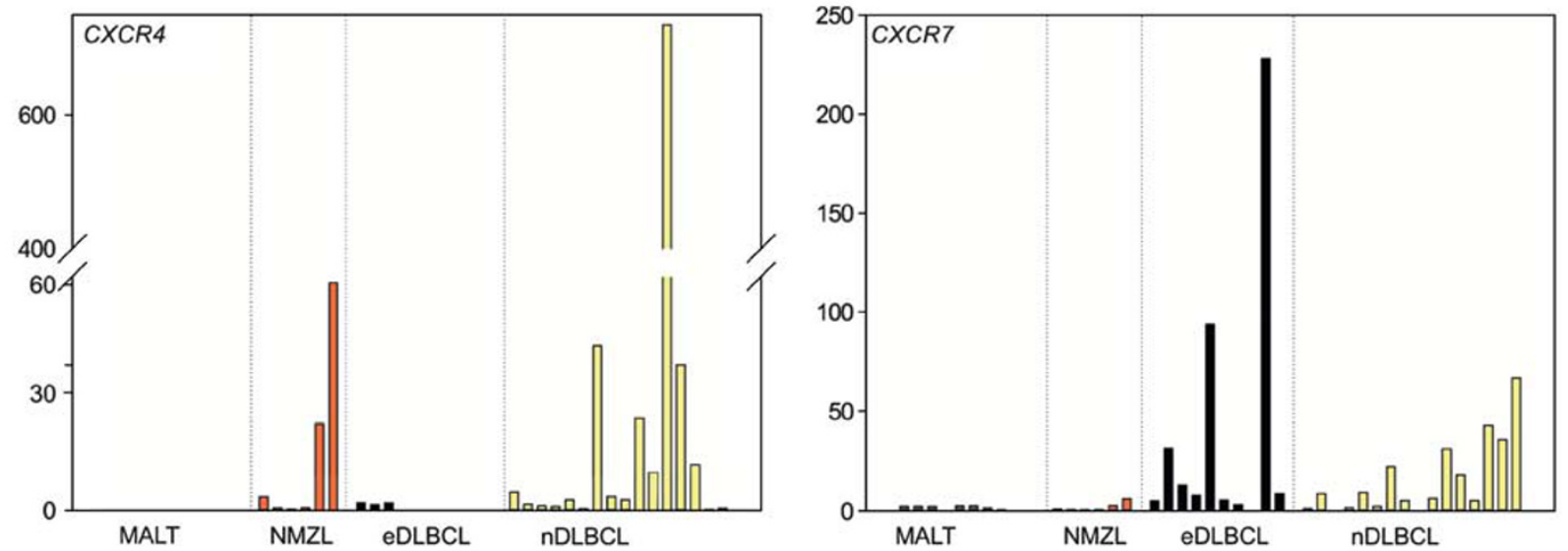

MALT $\square$ NMZL $\square$ eDLBCL $\square \mathrm{nDLBCL}$

c
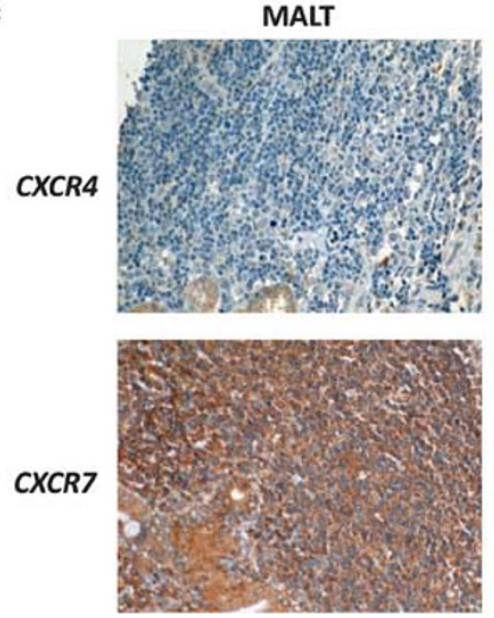

NMZL
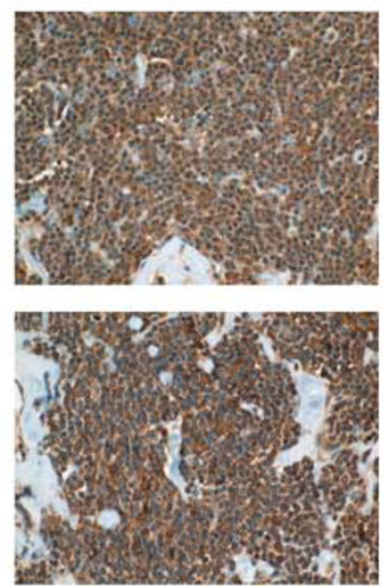

eDLBCL
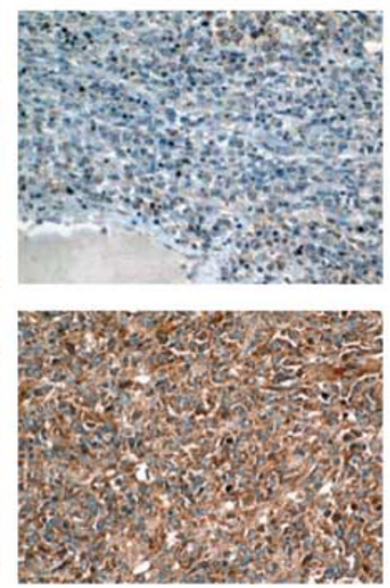

nDLBCL
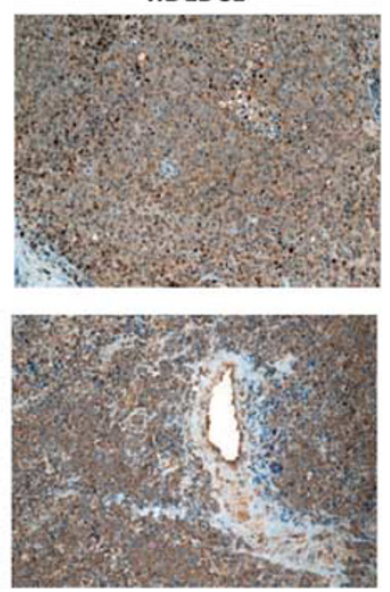

Figure 4 (a) CXCL12 expression in H. pylori-associated gastritis, gastric MALT lymphoma and gastric extranodal diffuse large B-cell lymphoma. (b) CXCR4 and CXCR7 expression in extranodal and nodal lymphomas on mRNA levels. Each bar represents a specimen. Values of gene expression are calculated as relative expression. (c) CXCR4 and CXCR7 immunohistochemical analyses in nodal and extranodal lymphomas. CXCR4 staining is restricted to nodal lymphomas, ie, diffuse large B-cell lymphoma and nodal marginal zone B-cell lymphoma; on the contrary CXCR4 is entirely lacking in lymphomas with extranodal manifestation, ie, MALT lymphoma and extranodal diffuse large B-cell lymphoma. eDLBCL, gastric extranodal diffuse large B-cell lymphoma; HP, $H$. pylori-associated gastritis; MALT, gastric MALT lymphoma; nDBLCL, nodal diffuse large B-cell lymphoma; NMZL, nodal marginal zone B-cell lymphoma.

During the development of $H$. pylori-associated gastritis, the B-cell homeostatic chemokine receptors CCR7, CXCR4 and CXCR5 were de novo expressed and the activation-dependent chemokine receptor XCR1 was downregulated $(P<0.001)$. During the transformation to gastric MALT lymphoma from H. pylori-associated gastritis, CCR7, CXCR3 and CXCR7 were upregulated, whereas CXCR4 lost its expression $(P<0.001)$. Upregulation of CXCR7 and absence of CXCR4 in the majority of MALT lymphoma cases was confirmed by immunohistochemical analyses (Tables 1 and 3, Figure 3). 
Table 4 CXCR4 expression and bone marrow infiltration of gastric MALT lymphoma, nodal marginal zone B-cell lymphoma, gastric extranodal diffuse large B-cell lymphoma and nodal diffuse large B-cell lymphoma

\begin{tabular}{|c|c|c|c|c|c|c|c|c|}
\hline & \multicolumn{2}{|l|}{$M A L T$} & \multicolumn{2}{|l|}{$N M Z L$} & \multicolumn{2}{|l|}{$e D L B C L$} & \multicolumn{2}{|c|}{$n D L B C L$} \\
\hline & $\%$ & IRS & $\%$ & IRS & $\%$ & IRS & $\%$ & IRS \\
\hline $\begin{array}{l}\text { CXCR4 } \\
\text { Bone marrow infiltration }\end{array}$ & $\begin{array}{c}2.8 \%(<1-5) \\
19 \%(4 / 21)\end{array}$ & 0.14 & $\begin{array}{c}82.5 \%(50-90) \\
67 / \%(4 / 6)^{\mathrm{a}}\end{array}$ & 12.75 & $\begin{array}{c}12.5 \%(0-50) \\
0 \%(0 / 8)\end{array}$ & 0.39 & $\begin{array}{c}75 \%(50-90) \\
50 \%(8 / 16)^{\mathrm{b}}\end{array}$ & 10.25 \\
\hline
\end{tabular}

Abbreviations: eDLBCL, extranodal diffuse large B-cell lymphoma; IRS, immunoreactive score; MALT, gastric MALT lymphoma; nDLBCL, nodal DLBCL; NMZL, nodal marginal zone B-cell lymphoma.

${ }^{a} P<0.05$ compared with MALT lymphoma.

${ }^{\mathrm{b}} P<0.05$ compared with extranodal diffuse large B-cell lymphoma.

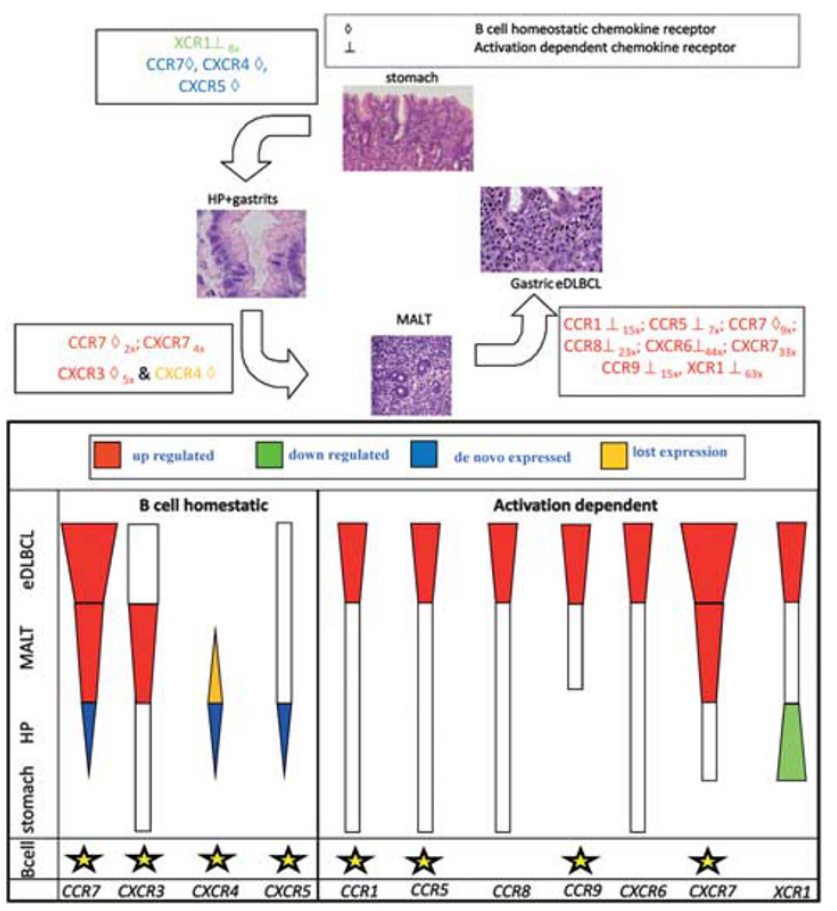

Figure 5 Overview of significant changes in the chemokine receptor expression profile during the gastric MALT lymphomagenesis for 19 chemokine receptors at mRNA levels. (a) In the development of $H$. pylori-associated gastritis, CCR7, CXCR4 and CXCR5 were de novo expressed and XCR1 was downregulated; progression to gastric MALT led to CCR7, CXCR3 and CXCR7 upregulation and loss of CXCR4; during the transformation of MALT to extranodal diffuse large B-cell lymphoma, CCR1, CCR5, CCR7, CCR8, CCR9, CXCR6, CXCR7 and XCR1 (numbers indicate magnitude of changes). (b) Graphical illustration of chemokine receptor expression divided into B-cell homeostatic, activationdependent chemokine receptors. Yellow stars depict expression of chemokine receptors in pCD19+ cells. eDLBCL, gastric extranodal diffuse large B-cell lymphoma; HP, H. pylori-associated gastritis; MALT, gastric MALT lymphoma; Stomach, nonneoplastic stomach.

Transformation of gastric MALT lymphoma to extranodal diffuse large B-cell lymphoma was accompanied by significant deregulation of seven activation-dependent chemokine receptors: upregulation of chemokine receptors CCR 1, CCR 5 , CCR 8 ,
CCR9, CXCR6, CXCR7 and XCR1 (Figures 1 and 2; Table 2); further, in the group of B-cell homeostatic chemokine receptors, CCR7 and CXCR3 were also significantly upregulated.

\section{Discussion}

This study was designed to investigate the expression pattern of B-cell homeostatic and activationdependent chemokine receptors in the development of gastric MALT lymphoma and extranodal diffuse large B-cell lymphoma of the stomach. We observed deregulated expression of 4 of 5 B-cell homeostatic B-cell receptors-CCR7, CXCR3, CXCR4 and CXCR5-and of 7 of 13 activation-dependent chemokine receptors-CCR1, CCR5, CCR8, CCR9, CXCR6, CXCR7 and XCR1-in both lymphoma entities. Some of these chemokine receptors have already been described in MALT lymphoma and in diffuse large B-cell lymphoma likewise by several authors. ${ }^{9,11,16,29-31}$

In our study, CCR9 mRNA expression significantly correlated with the proliferation rate in both lymphoma entities and its protein expression was restricted to malignant $\mathrm{B}$ cells with a significantly higher occurrence on extranodal diffuse large B-cell lymphoma cells. Expression of CCR9 was described to be localized on gut-homing $B$ and T cells having a role in mucosal immune response. ${ }^{32,33}$ CCL25-the ligand of $C C R 9^{34}$-was found to be induced by $H$. pylori infection leading to an accumulation of CCR9 + cells in the stomach in a mouse model of $H$. pylori-induced gastritis. ${ }^{35}$ Immunohistochemical analyses of chemokine receptors showed aberrant expression of CCR9 in mediastinal large B-cell lymphomas compared with diffuse large B-cell lymphomas, suggesting a role in the extranodal localization of lymphomas for this receptor. ${ }^{32}$ Besides the homing properties, anti-apoptotic and proliferating effects have been described for CCR9 in cancer cell lines. ${ }^{33}$ As CCR9 was expressed in MALT lymphoma and extranodal diffuse large B-cell lymphoma likewise, we hypothesize that CCR9 might have a role in the extranodal lymphoma localization of the 
stomach and that it may be involved in the transformation of the low proliferating MALT lymphoma to the high proliferating extranodal diffuse large B-cell lymphoma.

In the stepwise development from $H$. pyloriassociated gastritis to gastric MALT lymphoma, three of five B-cell homeostatic chemokine receptors and two activation-dependent chemokine receptors were deregulated. In $H$. pylori-associated gastritis, recruitment of $\mathrm{T}$ - and $\mathrm{B}$ cells, dendritic cells and neutrophil granulocytes is mediated by a variety of chemokines interacting with their cognate receptors such as CCR7, CCR5, CXCR1 and CXCR4 expressed on infiltrating immunological cells. ${ }^{30,36-41}$ Consistent with these findings, we also observed upregulated mRNA transcripts of CCR8, CCR9, CXCR3 and CXCR7.

During the development of gastric MALT lymphoma from $H$. pylori-associated gastritis, CXCR4 expression was lost and CXCR7 was upregulated. Immunohistochemistry underscored the loss of CXCR4 in MALT lymphoma cells. Additionally, CXCR7 expression was associated with the proliferation rate of gastric MALT lymphomas and extranodal diffuse large B-cell lymphoma in our study. CXCL12-the ligand of CXCR4 and CXCR $7^{20-22}-$ has been linked to multiple key processes in tumor cells, including proliferation, survival, migration, invasion and metastasis in more than 20 different types of cancer, ${ }^{42-49}$ providing evidence for the importance of this chemokine signaling pathway in cancer. CXCR7 expression was described in malignant cell types, in fetal liver cells and on tumor-associated blood vessels but not in normal vessels. ${ }^{2,50}$ CXCR7 transcripts were also detected in marginal zone $\mathrm{B}$ cells and their precursors but not in blood B cells. ${ }^{51,52}$ Interaction of CXCL12 with CXCR7 promotes tumor growth, proliferation and pro-survival effects ${ }^{18,50,53,54}$ in contrast to CXCR4, which mediates chemotaxis. ${ }^{55}$ Our observation that CXCR4 expression was lost during the transformation process of non-malignant marginal B cells to MALT lymphoma suggests that CXCL12 signals through binding to CXCR7 in MALT lymphoma and extranodal diffuse large B-cell lymphoma cells instead of signaling through CXCR4 and CXCR7 in non-malignant marginal $B$ cells. This may cause proliferative and pro-survival effects in the lymphoma cells. As pharmacological blockage of the interaction of CXCL12 with CXCR7 leads to retention of marginal zone B cells in the splenic marginal zone ${ }^{56}$ it might be speculated that CXCR7-CXCL12 interaction is essential for the homing process of MALT lymphoma and extranodal diffuse large B-cell lymphoma cells to the gastric mucosa.

CXCR4 expression is associated with bone marrow infiltration in our cohort of nodal diffuse large B-cell lymhoma and nodal marginal zone B-cell lymphoma. CXCR4 functions as a homing factor of malignant and normal hematopoietic stem cells of solid tumor cells to the bone marrow microenvironment, as well as of a
Burkitt's lymphoma cell line subcutaneously implanted into NOD/SCID mouse. ${ }^{23-28,57}$ In our cohort of extranodal and nodal lymphomas, we observed a lower frequency of bone marrow involvement in extranodal lymphomas as also described in other studies. ${ }^{58,59}$ Our data indicate that the loss of CXCR4 in extranodal lymphomas might explain the lower incidences of bone marrow involvement of gastric MALT lymphomas and extranodal diffuse large B-cell lymphomas compared with nodal marginal zone B-cell lymphomas and nodal diffuse large B-cell lymphomas. Bone marrow involvement is associated with a poor prognosis in nodal diffuse large B-cell lymphomas, ${ }^{60}$ and therefore CXCR 4 might be a valuable prognostic marker for bone marrow infiltration of nodal diffuse large B-cell lymphomas and hence represents a potential new target for lymphoma therapies.

During the transformation from gastric MALT lymphoma to extranodal diffuse large B-cell lymphoma, upregulation of CCR1, CCR5, CCR8 and CXCR7representative for activation-dependent chemokine receptors-and of CCR7, a B-cell homeostatic chemokine receptor, was observed. Further, CCR 9 and XCR1 were upregulated. A similar upregulation of CCR1 and CCR5 during the transformation process of extragastric MALT lymphoma was recently reported by us. ${ }^{16}$ CCR 8 and XCR1 expression has not yet been described in gastric extranodal diffuse large B-cell lymphoma so far. As CCR8 mediates rescue from steroid-induced apoptosis via an ERK-dependent pathway, it is conceivable that anti-apoptotic effects may contribute to high-grade transformation. ${ }^{58,59}$ Functional characterization of XCR 1 in oral squamous cell carcinoma cell lines show invasive and proliferative effects, ${ }^{61}$ suggesting a crucial role of XCR1 expression during transformation from MALT lymphoma to an aggressive lymphoma.

In summary, our data suggest that the development of gastric MALT lymphoma is associated with increased CCR7, CXCR3 and CXCR7 expression and a loss of CXCR4. The high-grade transformation is accompanied by upregulation of CCR 1, CCR 5 , CCR8, CCR9, CXCR7 and XCR1. In MALT lymphoma, the CXCR7 pathway seems to be responsible for the homing process to the gastric mucosa, whereas homing to the bone marrow microenvironment in nodal diffuse large B-cell lymphoma, and marginal zone B-cell lymphoma seems to be guided by CXCR4. Also, for the site of lymphoma manifestation (nodal vs extranodal), a differential regulation of CXCR4 and CXCR7 seems to be key determinants. Exploring distinct pathways in gastric MALT lymphomagenesis is a crucial step for the future development of new targeted therapies.

\section{Acknowledgements}

This work was supported in part by grants of Austrian Cancer Aid/Styria, Jubiläumsfond der 
ÖNB (11181 and 9895) and Austrian Science Fund (P15591, P18630 and FFG, Grant N211-NAN; DS) and the Adult Stem Cell Research Foundation $\left(\mathrm{TASC}^{\mathrm{RF}}\right.$ ).

\section{Disclosure/conflict of interest}

The authors declare no conflict of interest.

\section{References}

1 Isaacson PG. Du M-Q. MALT lymphoma: from morphology to molecules. Nat Rev Cancer 2004;4:644.

2 Campbell DJ, Kim CH, Butcher EC. Chemokines in the systemic organization of immunity. Immunol Rev 2003;195:58-71.

3 Laurence AD. Location, movement and survival: the role of chemokines in haematopoiesis and malignancy. Br J Haematol 2006;132:255-267.

4 Balkwill F. Cancer and the chemokine network. Nat Rev Cancer 2004;4:540-550.

5 Bowman EP, Campbell JJ, Soler D, et al. Developmental switches in chemokine response profiles during B cell differentiation and maturation. J Exp Med 2000;191: 1303-1318.

6 Cyster JG. Chemokines, sphingosine-1-phosphate, and cell migration in secondary lymphoid organs. Annu Rev Immunol 2005;23:127-159.

7 Muller G, Hopken UE, Lipp M. The impact of CCR7 and CXCR5 on lymphoid organ development and systemic immunity. Immunol Rev 2003;195:117-135.

8 Trentin L, Agostini C, Facco M, et al. The chemokine receptor CXCR3 is expressed on malignant B cells and mediates chemotaxis. J Clin Invest 1999;104:115-121.

9 Trentin L, Cabrelle A, Facco M, et al. Homeostatic chemokines drive migration of malignant B cells in patients with non-Hodgkin lymphomas. Blood 2004; 104:502-508.

10 Ohshima K, Suefuji H, Karube K, et al. Expression of chemokine receptor CXCR3 and its ligand, mig, in gastric and thyroid marginal zone lymphomas. Possible migration and autocrine mechanism. Leuk Lymphoma 2003;44:329-336.

11 Suefuji H, Ohshima K, Karube K, et al. CXCR3-positive $B$ cells found at elevated frequency in the peripheral blood of patients with MALT lymphoma are attracted by MIG and belong to the lymphoma clone. Int J Cancer 2005;114:896-901.

12 Golay J, Introna M. Chemokines and antagonists in non-Hodgkin's lymphoma. Expert Opin Ther Targets 2008;12:621-635.

13 Jaffe ES, Harris NL, Stein H, et al. World Health Organisation Classification of Tumors, Pathology and Genetics of Tumors of Haematopoietic and Lymphoid Tissues. IARC Press: Lyon, France, 2001.

14 Chan JK, Ng CS, Isaacson PG. Relationship between high-grade lymphoma and low-grade B-cell mucosaassociated lymphoid tissue lymphoma (MALToma) of the stomach. Am J Pathol 1990;136:1153.

15 Tsuji S, Hisaoka M, Morimitsu Y, et al. Detection of SYT-SSX fusion transcripts in synovial sarcoma by reverse transcription-polymerase chain reaction using archival paraffin-embedded tissues. Am J Pathol 1998;153:1807-1812.
16 Deutsch AJ, Aigelsreiter A, Steinbauer E, et al. Distinct signatures of B-cell homeostatic and activation-dependent chemokine receptors in the development and progression of extragastric MALT lymphomas. J Pathol 2008;215:431-444

17 Seidl H, Richtig E, Tilz H, et al. Profiles of chemokine receptors in melanocytic lesions: de novo expression of CXCR6 in melanoma. Hum Pathol 2007;38:768.

18 Infantino S, Moepps B, Thelen M. Expression and regulation of the orphan receptor RDC1 and its putative ligand in human dendritic and B cells. J Immunol 2006;176:2197-2207.

19 Neote K, DiGregorio D, Mak JY, et al. Molecular cloning, functional expression, and signaling characteristics of a C-C chemokine receptor. Cell 1993;72: 415-425.

20 Ehtesham M, Yuan X, Kabos P, et al. Glioma tropic neural stem cells consist of astrocytic precursors and their migratory capacity is mediated by CXCR4. Neoplasia 2004;6:287-293.

21 Zhang L, Yeger H, Das B, et al. Tissue microenvironment modulates CXCR4 expression and tumor metastasis in neuroblastoma. Neoplasia 2007;9:36-46.

22 Burns JM, Summers BC, Wang Y, et al. A novel chemokine receptor for SDF-1 and I-TAC involved in cell survival, cell adhesion, and tumor development. J Exp Med 2006;203:2201-2213.

23 Gillette JM, Larochelle A, Dunbar CE, et al. Intercellular transfer to signalling endosomes regulates an ex vivo bone marrow niche. Nat Cell Biol 2009;11:303-311.

24 Hayakawa J, Migita M, Ueda T, et al. Dextran sulfate and stromal cell derived factor-1 promote CXCR4 expression and improve bone marrow homing efficiency of infused hematopoietic stem cells. J Nippon Med Sch 2009;76:198-208.

25 Kyriakou C, Rabin N, Pizzey A, et al. Factors that influence short-term homing of human bone marrowderived mesenchymal stem cells in a xenogeneic animal model. Haematologica 2008;93:1457-1465.

26 Taichman RS, Cooper C, Keller ET, et al. Use of the stromal cell-derived factor-1/CXCR4 pathway in prostate cancer metastasis to bone. Cancer Res 2002;62: 1832-1837.

27 Sun YX, Wang J, Shelburne CE, et al. Expression of CXCR4 and CXCL12 (SDF-1) in human prostate cancers (PCa) in vivo. J Cell Biochem 2003;89:462-473.

28 Kang Y, Siegel PM, Shu W, et al. A multigenic program mediating breast cancer metastasis to bone. Cancer Cell 2003;3:537-549.

29 Jones D, Benjamin RJ, Shahsafaei A, et al. The chemokine receptor CXCR3 is expressed in a subset of B-cell lymphomas and is a marker of B-cell chronic lymphocytic leukemia. Blood 2000;95:627-632.

30 Mazzucchelli L, Blaser A, Kappeler A, et al. BCA-1 is highly expressed in Helicobacter pylori-induced mucosa-associated lymphoid tissue and gastric lymphoma. J Clin Invest 1999;104:R49-R54.

31 Rodig SJ, Jones D, Shahsafaei A, et al. CCR6 is a functional chemokine receptor that serves to identify select B-cell non-Hodgkin's lymphomas. Hum Pathol 2002;33:1227-1233.

32 Rehm A, Anagnostopoulos I, Gerlach K, et al. Identification of a chemokine receptor profile characteristic for mediastinal large B-cell lymphoma. Int J Cancer 2009;125:2367-2374.

33 Shen X, Mailey B, Ellenhorn JD, et al. CC chemokine receptor 9 enhances proliferation in pancreatic 
intraepithelial neoplasia and pancreatic cancer cells. J Gastrointest Surg 2009;13:1955-1962.

34 Kunkel EJ, Campbell JJ, Haraldsen G, et al. Lymphocyte CC chemokine receptor 9 and epithelial thymusexpressed chemokine (TECK) expression distinguish the small intestinal immune compartment: Epithelial expression of tissue-specific chemokines as an organizing principle in regional immunity. J Exp Med 2000;192:761-768.

35 Kiriya K, Watanabe N, Nishio A, et al. Essential role of Peyer's patches in the development of Helicobacterinduced gastritis. Int Immunol 2007;19:435-446.

$36 \mathrm{Wu}$ Y-Y, Tsai H-F, Lin W-C, et al. Upregulation of CCL20 and recruitment of CCR6 + gastric infiltrating lymphocytes in Helicobacter pylori gastritis. Infect Immun 2007;75:4357-4363.

37 Yoshida A, Isomoto H, Hisatsune J, et al. Enhanced expression of CCL20 in human Helicobacter pyloriassociated gastritis. Clin Immunol 2009;130:290-297.

38 Galamb O, Gyorffy B, Sipos F, et al. Helicobacter pylori and antrum erosion-specific gene expression patterns: the discriminative role of CXCL13 and VCAM1 transcripts. Helicobacter 2008;13:112-126.

39 Hansson M, Hermansson M, Svensson H, et al. CCL28 is increased in human Helicobacter pylori-induced gastritis and mediates recruitment of gastric immunoglobulin a-secreting cells. Infect Immun 2008;76: 3304-3311.

40 Hansson M, Lundgren A, Elgbratt K, et al. Dendritic cells express CCR7 and migrate in response to CCL19 (MIP-3[beta]) after exposure to Helicobacter pylori. Microb Infect 2006;8:841-850.

41 Schmausser B, Endrich S, Brandlein S, et al. The chemokine receptor CCR7 is expressed on epithelium of non-inflamed gastric mucosa, Helicobacter pylori gastritis, gastric carcinoma and its precursor lesions and up-regulated by $H$. pylori. Clin Exp Immunol 2005;139:323-327.

42 Smith MC, Luker KE, Garbow JR, et al. CXCR4 regulates growth of both primary and metastatic breast cancer. Cancer Res 2004;64:8604-8612.

43 Muller A, Homey B, Soto $\mathrm{H}$, et al. Involvement of chemokine receptors in breast cancer metastasis. Nature 2001;410:50-56.

44 Kollmar O, Rupertus K, Scheuer C, et al. Stromal cellderived factor-1 promotes cell migration and tumor growth of colorectal metastasis. Neoplasia 2007;9: 862-870.

45 Engl T, Relja B, Marian D, et al. CXCR4 chemokine receptor mediates prostate tumor cell adhesion through alpha5 and beta3 integrins. Neoplasia 2006;8: 290-301.

46 Sung B, Jhurani S, Ahn KS, et al. Zerumbone downregulates chemokine receptor CXCR4 expression leading to inhibition of CXCL12-induced invasion of breast and pancreatic tumor cells. Cancer Res 2008; 68:8938-8944.
47 Marlow R, Strickland P, Lee JS, et al. SLITs suppress tumor growth in vivo by silencing Sdf1/Cxcr4 within breast epithelium. Cancer Res 2008;68:7819-7827.

48 Schabath H, Runz S, Joumaa S, et al. CD24 affects CXCR4 function in pre-B lymphocytes and breast carcinoma cells. J Cell Sci 2006;119:314-325.

49 Holland JD, Kochetkova M, Akekawatchai C, et al. Differential functional activation of chemokine receptor CXCR4 is mediated by $\mathrm{G}$ proteins in breast cancer cells. Cancer Res 2006;66:4117-4124.

50 Miao Z, Luker KE, Summers BC, et al. CXCR7 (RDC1) promotes breast and lung tumor growth in vivo and is expressed on tumor-associated vasculature. Proc Natl Acad Sci USA 2007;104:15735-15740.

51 Sierro F, Biben C, Martinez-Munoz L, et al. Disrupted cardiac development but normal hematopoiesis in mice deficient in the second CXCL12/SDF-1 receptor, CXCR7. Proc Natl Acad Sci USA 2007;104: 14759-14764.

52 Zhang P, Li W, Wang Y, et al. Identification of CD36 as a new surface marker of marginal zone $B$ cells by transcriptomic analysis. Mol Immunol 2007;44:332-337.

53 Wang J, Shiozawa Y, Wang Y, et al. The role of CXCR7/ RDC1 as a chemokine receptor for CXCL12/SDF-1 in prostate cancer. J Biol Chem 2008;283:4283-4294.

54 Mazzinghi B, Ronconi E, Lazzeri E, et al. Essential but differential role for CXCR4 and CXCR7 in the therapeutic homing of human renal progenitor cells. J Exp Med 2008;205:479-490.

55 Balkwill F. The significance of cancer cell expression of the chemokine receptor CXCR4. Semin Cancer Biol 2004;14:171-179.

56 Wang H, Beaty N, Chen S, et al. The CXCR7 chemokine receptor promotes B-cell retention in the splenic marginal zone and serves as a sink for CXCL12. Blood 2011;119:465-468.

57 Beider K, Ribakovsky E, Abraham M, et al. CXCR4 antagonist BKT140 synergizes with rituximab, targeting non Hodgkin lymphoma (NHL) in vitro and in vivo in a xenograft model with bone marrow involvement. ASH Annu Meet Abstr 2011;118:952.

58 Gutierrez-Garcia G, Colomo L, Villamor $\mathrm{N}$, et al. Clinico-biological characterization and outcome of primary nodal and extranodal diffuse large B-cell lymphoma in the rituximab era. Leuk Lymphoma 2010;51:1225-1232.

59 Lopez-Guillermo A, Colomo L, Jimenez M, et al. Diffuse large B-cell lymphoma: clinical and biological characterization and outcome according to the nodal or extranodal primary origin. J Clin Oncol 2005;23: 2797-2804.

60 Viswanatha D, Foucar K. Hodgkin and non-Hodgkin lymphoma involving bone marrow. Semin Diagn Pathol 2003;20:196-210.

61 Khurram SA, Whawell SA, Bingle L, et al. Functional expression of the chemokine receptor XCR1 on oral epithelial cells. J Pathol 2010;221:153-163.

Supplementary Information accompanies the paper on Modern Pathology website (http://www.nature.com/ modpathol) 